\title{
El proyecto de un palacio virreinal para México del primer arquitecto americano graduado en España
}

\begin{abstract}
71 propósito de esta investigación es analizar uno de los escasos intentos de formación de profesionales americanos en las instituciones académicas españolas durante el virreinato. Si bien en México se habría de formar la Academia de San Carlos, el poder centralizador de la corona exigía que los proyectos de obras civiles o religiosas realizados en territorio americano fueran aprobados por la Real Academia de San Fernando en Madrid para autorizar su construcción. Ello era compatible con la intención de que la Academia fuese "un instrumento que sirviera para ejercer el control de la arquitectura en Espańa y que estuviera estrechamente vinculado a la ideología del poder". ${ }^{\text {I }}$

Esta contextualización de la circunstancia del ejercicio del poder de la Ilustración en España ratificaría la actitud de control. Así, la Academia de San Fernando "difusora del nuevo gusto, empeñada en reconocer el estatuto de autonomía para el arquitecto y su obra, defensora de un aprendizaje — en consonancia con lo anterior- más teórico, fue también el freno principal para la expansión de aquel ideal de arquitectura que desbordaba esas modestas pretensiones antes señaladas". ${ }^{2}$
\end{abstract}

I. Pedro Navascués, "La arquitectura neoclásica. (1750-1833)", en Historia del arte hispánico. Del neoclasicismo al modernismo, eds. Pedro Navascués y Carlos Pérez Reyes (Madrid: Alhambra, 1978), 4.

2. Javier Hernando, Arquitectura en España. 1770-1900 (Madrid: Cátedra, 1989), 47. 
De la misma manera el control de la formación y actuación en el otro campo profesional calificado, el del real cuerpo de ingenieros militares, se mantuvo en la Península. Sorprendentemente las propuestas de crear una Academia en América, donde Espańa gastaba la mayor cantidad de sus inversiones en fortificaciones, fueron denegadas, mientras este tipo de corporaciones se creaban en Ceuta y Argel. Es pues evidente que hubo un interés político en la selección del emplazamiento de estos centros de formación y una desconfianza sobre la capacitación militar de los americanos. Muy pocos de los nacidos en América accedieron, en la última fase del dominio espańol, a la formación en Alcalá de Henares, Cádiz o Guadalajara, donde itineró la antigua Academia de Barcelona.

En este contexto en el que las presentaciones, realizadas por alumnos y profesores de la Academia de San Carlos de la Nueva Espańa, eran lapidariamente rechazadas por los arquitectos metropolitanos, la presencia de un alumno mexicano aventajado, que obtuvo su título de arquitecto, es de por sí un tema sorprendente que entendemos merece ser conocido y ponderado. Esta primera aproximación tiene como objetivo difundir la circunstancia de su trayectoria y, a la vez, considerar los elementos que hicieron posible la formación del arquitecto a comienzos del siglo XIX.

El tiempo en el que este profesional de nacionalidad mexicana se formó en la Península Ibérica estuvo marcado por los acontecimientos que generó la invasión y ocupación napoleónica, lo cual significó la paralización de toda obra pública o privada en un escenario de guerra total. Por ello, su eventual inserción en un contexto más general de la producción arquitectónica europea careció de posibilidades, como de hecho le hubiera sucedido si hubiese permanecido y se hubiese formado en México en tiempos de la independencia de su país.

Probablemente no era éste el panorama profesional que tuvo Francisco de Paula de la Vega y Pérez durante sus estudios. En la escala de grandezas que suponían por entonces los trabajos académicos, se decantaría por proponer un gran proyecto para Palacio Virreinal en México. Tal fue el tema elegido para el examen de graduación que se le impuso y en el que demostró su solvencia profesional en los términos de las exigencias que la Academia requería (véase "Anexo"). El argumento que se desarrolla en este artículo trata justamente sobre la trayectoria de este personaje en Espańa.

En años posteriores también se reconoció al mexicano ingeniero militar Mariano Carrillo de Albornoz, nacido en Oaxaca, como miembro de la Aca- 
demia. Él estaba vinculado a los ejércitos realistas y se consideró meritorio por sus tratados sobre topografía y arquitectura ${ }^{3}$ y muy especialmente por sus trabajos en la isla de Cuba a mediados del siglo XIX.

\section{El sistema de enseñanza de la Real Academia de Bellas Artes de San Fernando a principios del siglo XIX}

Al tener en cuenta lo acuciados que estaban quienes aspiraban a ser nominados como arquitectos, por la lentitud de las pruebas que se exigían en la Academia, el rey sancionó el 29 de julio de I8or una real orden sobre los ejercicios de delineación y examen para la graduación y título de los maestros arquitectos de San Fernando. ${ }^{4}$ La nueva legislación establecía que los aspirantes harían planos de un edificio de su invención y el cálculo detallado de su costo, así como el método de construcción. De allí pasaría el proyecto a la Comisión de Arquitectura, creada en 1786 y, en caso de aprobarse, se remitiría a la Junta Ordinaria de la Academia.

Este proyecto formalizaba la llamada "Prueba de Pensado" y su aprobación lo facultaba para la otra prueba "de Repente". Para realizar este examen debía presentar previamente un certificado en el cual se confirmara que había realizado una práctica como asistente de obra de un arquitecto ya aprobado por la Academia. Los ejercicios "de Repente" se extraerían de los temas que hubiesen sido examinados anteriormente por la Academia, entre ellos se escogerían por sorteo tres y el postulante habría de elegir uno de ellos. La prueba se realizaría de continuo entre las 7 de la mañana y las ıo de la noche, sin permitirle salir del aula, aunque podía contar con "los libros clásicos de arquitectura que el pretendiente necesite" y que se encontraran en la biblioteca de la Academia.

Después de esto, el candidato debía ser examinado por el jurado sobre diversos aspectos de la formación del profesional, fundamentalmente de índo-

3. Tradujo también los Elementos de arquitectura, de John Millington (trad., notas y apéndices de Mariano Carrillo de Albornoz [Madrid, Imprenta Nacional, I840]).

4. Archivo de la Real Academia de Bellas Artes de San Fernando (en adelante arabasf), "Real Orden del 29 de julio de I8Or en que S.M. establece las pruebas de delineación y de examen a que han de sujetarse los profesores de arquitectura que deseen conseguir la graduación y título de maestros arquitectos en la Real Academia de San Fernando”, núm. I86-5/I, impreso. 
le matemática, teórica y práctica que permitiera asegurar su idoneidad y pericia en el oficio.

Paulatinamente los estudios de la Academia, cuestionados por ser demasiado teóricos y centrados en la calidad del dibujo y menos en el conocimiento de la construcción, habían de ir dando espacio a mayores conocimientos técnicos y a la realización de pruebas más exigentes en el interrogatorio sobre diversos aspectos de la disciplina. 5

Aunque no muy frecuente, la opción por emprender un diseńo de Palacio Real o Virreinal no fue ajena a las propuestas de los aspirantes a académicos de mérito en arquitectura en la Academia de Bellas Artes de San Fernando. En general hasta finales del siglo XviII predominaba en los diseños de los alumnos el discurso retórico de la magnificencia monumentalista de la monarquía. ${ }^{6}$ Sin embargo, será el propio Juan de Villanueva quien ratificará la poca entidad y calidad de las obras públicas realizadas por los egresados de la Academia al tratar de renovar el contenido de la enseñanza.7

Quizá como consecuencia de ello el nivel de exigencias pudo haber crecido. En 1792, por ejemplo, Francisco Martín del Horcajo y Vidal presentaba como ejercicio un Palacio Real. Su prueba no resultó del valor esperado por el jurado que la reprobó y solamente le dieron título de maestro de obras. ${ }^{8}$ A principios del siglo xix Agustín de Bentancourt denunciaba que la Academia habilitaba a arquitectos que no sabían realizar las obras de infraestructura y que ésta requería una modificación a fondo. ${ }^{9}$

Sin embargo, desde mediados del siglo XviII se habían intentado definir, por parte del arquitecto y ensamblador Manuel Losada, que había trabajado en las obras de Aranjuez, ciertas reglas sobre las trazas de un palacio real. Para ello, y apelando a las matemáticas y la geometría, manifestaba haber encontrado un método de diseño, hasta ese momento no utilizado para proyectar

5. José Caveda, Memorias para la historia de la Real Academia de Bellas Artes de San Fernando y de las Bellas Artes en España, desde el advenimiento al trono de Felipe V hasta nuestros días (Madrid: Real Academia de Bellas Artes, I867).

6. Ramón Gutiérrez y Cristina Esteras, Arquitectura y fortificación de la Ilustración a la Independencia americana (Madrid: Tuero, 1993).

7. José Enrique García Melero, La Real Academia de San Fernando en 1792 (Madrid: Real Academia de Bellas Artes, 1992).

8. arabasf, Archivo de Planos en la Biblioteca, "Examen del 2 de junio de I793", núm. I624 a I629.

9. Pedro García Ormaechea, "Bentancourt y la Academia de Bellas Artes", Revista de Obras Públicas (febrero-octubre, 1964). 
un suntuoso palacio. En 1740 se le sería la edición de su libro que financiaría parte de una colección de diez tomos sobre diversos temas de arquitectura, del cual solamente se editaría el primero. ${ }^{\text {Io }}$

Losada planteaba que lo fundamental en el diseño de un palacio era "su coordinada disposición”, ya que la composición exigía cinco cosas: simetría, firmeza, proporción entre las partes, comodidad y hermosura. Dada la complejidad de funciones que abarcaba el tema, Losada decía que un "Palacio Real es una ciudad abreviada" y en la definición de su programa mencionaba cinco temas: la habitación de los reyes, los cuarteles de soldados, las cocinas y reposterías, los picaderos y caballerizas y las cocheras y establos de mulas. ${ }^{I I}$

En su concepción el Palacio debería tener una traza en forma de cruz perfectísima que en el centro tendría la habitación de los reyes, al sur, los cuarteles, al este, las cocinas y repostería, al norte, los picaderos y al oeste, las cocheras. El diseño, presentado por parte de De la Vega y Pérez, dio menos relevancia a la parte de servicios de las caballerizas, pero agregó en el proyecto del Palacio todas las referencias a los protocolos de gobierno, la presencia de la audiencia, los tribunales y la cárcel. En comparación, la residencia del virrey, en este caso, ya no ocupa el centro del conjunto, aunque sea la parte que caracteriza el diseño.

\section{El proyecto del Palacio Virreinal en México}

El proyecto "de Pensado", propuesto por el mexicano Francisco de Paula de la Vega y Pérez en I804, era el de un "edificio destinado a la habitación del virrey de México y todos sus agregados, cuales son: audiencia, cárcel, juzgado de guerra, cuarteles y demás oficinas correspondientes al virreynato”. El diseño entrañaba de por sí bastante complejidad por las múltiples y variadas funciones que integró en el programa. Sin embargo, De la Vega y Pérez optó por no apartarse en absoluto del rigorismo clasicista y definió un partido arquitectónico de rotundas simetrías y ejes axiales.

Io. Manuel Losada, Critica y compendio especulativo-práctico de la architectura civil: el que demostrando reglas nuevas y fáciles para plantificar palacios y templos: da expedientes utilísimos para fabricar habitaciones y casas para toda clase, graduación y estado de personas. Tomo I: el que manifiesta reglas nuevas para edificar un Palacio Real jamás visto ni hasta ahora inventado (Madrid: Antonio Marín, 1740).

II. Losada, Crítica y compendio especulativo-práctico de la architectura civil, 29. 
Curiosamente, el cuerpo central del edificio de planta baja y de un plano superior principal pivotaría sobre un gran cuerpo edilicio central que albergaría a la audiencia, tribunales y juzgados en el nivel bajo. La parte de recepción protocolar del virrey se desarrollaría en la planta alta. Sobre el ala ubicada a la izquierda se alojarían los cuerpos de la guardia de honor y los recintos de la residencia virreinal, mientras que en el ala derecha estarían los espacios destinados a la cárcel y al cuartel de alabarderos.

La fragmentación espacial era notoria para cubrir las múltiples funciones y los planos evidencian en el ala derecha de la planta baja, 47 ámbitos para la guardia de honor y 27 para las habitaciones del virrey, y en el piso alto, 34 para cuartel y 48 para residencia. Sobre el ala izquierda había abajo 44 recintos para cárcel y nueve para los alabarderos, y arriba, 29 para cárcel y cinco para cuartel. El cuerpo central mantenía 43 ámbitos para la audiencia y sobre ellos otros 4I primordialmente destinados a las funciones públicas del virrey.

Un análisis de lo que debería ser el núcleo vital del conjunto nos muestra que las habitaciones del virrey y su familia ocupaban una porción reducida del diseño, al superar exclusivamente a la pequeña guarnición de alabarderos ubicada en la otra ala del edificio que custodiaba la zona de la cárcel. Por el contrario, el espacio de cuarteles destinado a la guardia de honor duplicaba la superficie de la residencia.

Las habitaciones del virrey tenían en planta baja un local para guardia particular, las cocinas, antecocinas y repostería con sus despensas, comedores de criados y señoras y dormitorio de criados. Otro conjunto lo formaban el cuarto de juego, las antesalas y las alcobas, las salas y gabinete desde donde se comunicaban a las galerías que formaban el hemiciclo, el cual rodeaba el jardín. Próximos a estos pasos al exterior estaban las piezas de bańo, de recreo, invernadas y estufas; las grutas, el cenador y el jardín con sus fuentes y la fuente pública, así como los "lugares comunes" (servicios sanitarios) generales. En la planta alta se encontraban las dependencias principales: las antesalas, la sala del estrado, el gabinete y la sala de labor. Junto a ellas las alcobas para los hijos con sus "retretes" y los gabinetes, así como el dormitorio de los criados de la señora. El oratorio con su sacristía franqueaba otra área donde se localizaba el cuarto de los criados de librea y las salas de tertulias, la de besamanos, la de refrescos y la de compañía e inclusive una sala reservada para el virrey y su señora. La parte de servicio que comunicaba con la planta baja tenía los comedores y aparadores, despensas y sala de vestuarios de funcionarios. El espacio público más ponderado estaba definido que el salón de 
funciones y la secretaría del virrey, zona de "comunes" y las salidas al jardín con sus escaleras y las comunicaciones a las cuadras, el pajar y los graneros.

En la parte posterior de la residencia virreinal se localizaba el real cuerpo de guardias del rey, fundado en 1704, que hasta I815, es decir en tiempos de este proyecto, contemplaba tres escuadrones al cual se agregaría luego otro denominado de flanqueadores de caballería. Más reducida resultaba la guardia de la cárcel a cargo del cuerpo de alabarderos formado en 1707. No tenemos certeza de que la presencia de estos regimientos, propios de la estructura militar defensiva del rey, estuvieran representados de la misma manera en México, de tal forma que el programa del diseńo parece atender al modelo peninsular reiterándolo en la Nueva España. ${ }^{\mathrm{I}}$

\section{La evaluación del proyecto}

En 1804 Francisco de Paula de la Vega y Pérez presentaba su "Prueba de Pensado" como aspirante al cargo de maestro arquitecto. Para cumplir con los requisitos de esta prueba debía entregar previamente un conjunto de diseños en hojas de gran tamaño dibujadas en tinta sepia. ${ }^{33}$ Los planos realizados en varas castellanas incluían los elementos esenciales, aunque prescindían de detalles y de diseños estructurales que luego exigiría la Academia en las décadas siguientes.

Este proyecto es uno de los escasos ejemplos en el cual los alumnos de la Academia muestran interés en tomar un tema americano y no resulta casual que el diseńador tuviera esa nacionalidad, por lo cual se asumía que era capaz de responsabilizarse de los condicionantes del sitio donde se realizaría. ${ }^{14}$ Sin embargo, el carácter del tema ubicado en la culminación paradigmática de las propuestas, puesto que se trataba del palacio de la máxima autoridad civil, tenía tanto en su programa cuanto en su resolución tipológica una total autonomía como para desarrollarse en cualquier contexto.

I2. Estado Militar de España (Madrid: Imprenta Real, i820).

I3. ARabasf, Archivo de Planos en la Biblioteca, "Plano general $(74.5 \times 94.2 \mathrm{~cm})$ ", núm. I648; "Planta baja $(84 \times 97.7 \mathrm{~cm})$ ", núm. I649; "Planta principal $(84 \times 96.2)$ ", núm. I650; "Fachada principal y Sección A-B $(55.6 \times 1.554$ cm)", núm. I651; y "Fachada posterior y sección C-D. $(55.7 \times 1.734 \mathrm{~cm}) "$, núm. 1652 .

I4. Silvia Arbaiza Blanco Spler y Carmen Heras Casas, "Inventarios de dibujos de arquitectura de los siglos XviII y xix en el Museo de la Real Academia de Bellas Artes de San Fernando", Academia, núms. IO2-I03 (2006): I84. 
En esto incidía particularmente el espíritu académico que atendía más a ciertas normativas de la composición arquitectónica, como la simetría axial y la jerarquización de los volúmenes, que a las incidencias del contexto en el cual se instalaba la obra. Es decir que la arquitectura tenía códigos de caracterización propios, los cuales la hacían valorable con una cierta independencia de su relación con el medio natural y cultural.

En mayo de 1804 De la Vega y Pérez habría de someterse a un tribunal de calificación que atendería a la calidad de su trabajo y a sus conocimientos teóricos. El jurado lo integraba Silvestre Pérez, vicesecretario de la Comisión de Arquitectura, quien recibió el proyecto del Palacio Virreinal con los anexos que incluían cuarteles, tribunales y otras oficinas anexas a él. También constaba un detallado informe facultativo con una estimación de costos que ascendía a 40.788 pesos y 589 reales. La comisión encontró mérito en el diseño de De la Vega y Pérez y dictaminó que se hallaba en condición de la ejecución de las otras pruebas prevenidas por la real orden y conformándose la Academia con este dictamen, se sortearon los tres programas de la "Prueba de Repente" que De la Vega debía responder al día siguiente eligiendo uno de ellos. ${ }^{\text {I5 }}$

La Junta de la Academia se habría de reunir el 8 de julio de I804 para considerar que a Francisco de Paula de la Vega y Pérez se le había admitido en la Junta Ordinaria del 6 de mayo cuando se le llamó "según el nuevo Reglamento, a ejecutar la Prueba de Repente para su graduación de maestro arquitecto". ${ }^{16}$

El proyecto fue evaluado positivamente, el acta correspondiente dice que "hallaron al discípulo Vega con las suficiencias necesarias en la teórica y práctica del arte para obtener en título de maestro arquitecto de lo cual enterada la Academia en la Junta Ordinaria de este día tuvo a bien conferirle dicha graduación y acordó que se le despachase el correspondiente título". El acta firmada por el secretario Isidoro Bosarte estaba acompañada por la opinión de Agustín de Betancourt, Pedro Arnal, Luis Munarriz, Antonio Aguado y Juan Antonio Cuervo. ${ }^{17}$

I5. arabasF, "Libro de Juntas, Comisión de Arquitectura, 6 de mayo de 1804", núms. 3-87, 83. 16. ARABASF, "Libro de Juntas que comienza el 2 de enero de I803", núms. 3-87, 98 y 99.

17. Muchos de estos académicos tuvieron relación con América. Munarriz intervino directamente en la formación de la Academia de San Carlos en México, Antonio Aguado hizo proyectos para el Río de la Plata y Juan Antonio Cuervo para Nueva Granada. Pedro Arnal fue quien buscó monopolizar el control arquitectónico en Espańa y sus dominios desde la Academia a partir de 1786 . 


\section{Francisco de Paula de la Vega y Pérez}

La presencia de Francisco de Paula de la Vega y Pérez en Madrid estuvo vinculada a la suerte de su hermano Pablo de la Vega, quien, como alumno de la Academia de San Carlos en México, fue beneficiado con una pensión para estudiar en la Real Academia de San Fernando en la corte en el año 1797 . $^{18}$

Cuando comenzó sus estudios por seis años con la tutoría de Cosme de Acuña, Pablo falleció, y su pensión fue trasladada en i8or a su hermano Francisco de Paula de la Vega y Pérez. ${ }^{19}$ Esta circunstancia nos hace pensar que si en 1804 Francisco de Paula estaba habilitado para dar sus pruebas de suficiencia es muy probable que ambos hermanos hubiesen estado juntos, ya que era requisito de la Academia de San Fernando que los postulantes en el campo de la arquitectura realizaran no solamente sus cursos dedicados a matemáticas, dibujo y teoría de la arquitectura sino que después de cuatro años debían dedicarse a realizar prácticas durante dos años junto a profesionales habilitados y atender al estudio de la montea. Esto presupondría que Francisco de Paula debió comenzar sus estudios entre I797 y 1798.

Graduado de arquitecto, De la Vega y Pérez se mudó en 1807 a Ciudad Rodrigo y actuó en la región de Salamanca. Menciona en I8I2 ser egresado de la Real Academia de San Fernando y también de la de la Nueva Espańa, lo cual solamente pudo serlo en función de un reconocimiento de su carácter de mexicano, no porque haya tenido tiempo de hacer nuevos estudios en México.

A nuestro arquitecto le tocó vivir directamente las circunstancias bélicas que presuponen la toma de la ciudad por las fuerzas napoleónicas del mariscal Ney y del general Masséna, en julio de i8ıo, las cuales derivaron en la voladura que el ejército inglés realizó del fuerte de la Concepción para que no cayese en manos de los franceses. ${ }^{20}$ Los daños generados por el ataque francés no habían sido reparados totalmente cuando en enero de I8I2 las tropas aliadas de ingleses, espańoles y portugueses, conducidas por el duque de Wellington

18. María Concepción García Sáiz y Carmen Rodríguez Tembleque, "Historia de un intento fallido: La Academia madrileńa para pensionados mexicanos", Cuadernos de Arte Colonial núm. 2 (Madrid: Museo de América, mayo de 1987).

I9. AgI, México, "Carta de Antonio Caballero a la Academia Real de San Carlos de la Nueva España el 3 de julio de I8oI", 2793.

20. Moisés Cayetano Rosado, "Las fortificaciones abaluartadas de La Raya desde el siglo xix hasta la actualidad", http://aviagemdosargonautas.net/2013/or/3o/, consultado el 7 de septiembre de 2013 . 
y futuro conde de Ciudad Rodrigo. ${ }^{21}$ En la toma de Ciudad Rodrigo falleció el general Crauford, quien ostentaba en su trayectoria la toma y la posterior derrota en las batallas de la ciudad de Buenos Aires en 1807 .

Fernando Cobos menciona que previo a estas acciones hubo un proyecto de los españoles realizado por el ingeniero Juan Belestá y dibujado por Nicolás Verdejo en abril de i8ıo el cual no alcanzó a realizarse y que tendía a reforzar las defensas frente a la amenaza francesa. Posteriormente a la toma en julio de I8Io, los franceses hicieron reparaciones y reforzaron las alturas de San Francisco con el reducto denominado Renaud, en homenaje al nuevo gobernador de la plaza. Probablemente en estas fortificaciones actuaron los ingenieros Couché y Belmas, comandante de los profesionales franceses.

Nuevamente, en poder de las fuerzas aliadas desde enero de i8I2, hubo una serie de obras proyectadas por los ingenieros ingleses comandados por el ingeniero Fletcher, quien diseñó los cinco reductos exteriores que se comenzaron a realizar por los espańoles desde finales de marzo de I8I2 bajo la dirección del ingeniero Ramón Calvet según planos dibujados por Juan Donoso. ${ }^{22}$

En I8I2 De la Vega y Pérez dijo ostentar el título de maestro mayor de las fortificaciones de la plaza de Ciudad Rodrigo y realizó un minucioso informe sobre los daños sufridos por la catedral que había servido provisoriamente de polvorín. ${ }^{23}$ Detallaba en la necesidad de reparar los tejados y armaduras de las capillas de Pilar y Dolores, los caballetes de la nave principal cuya ruina ocasionaría la caída de las tres naves, el arreglo de la fachada y la portada en forma de peristilo corintio, su cornisa y el frontis, así como el remate de la torre y la cornisas y dovelas de la cúpula entre otras acciones inmediatas.

El texto de Fernando Cobos y Joáo Campos, a pesar de ser el más documentado sobre las fortificaciones de Ciudad Rodrigo, no menciona la actuación de De la Vega y Pérez en una época en que confluían ingenieros franceses, ingleses,

2I. Fernando Cobos y João Campos, Almeida-Ciudad Rodrigo. Las fortificaciones en la raya central (Ciudad Rodrigo: Consorcio Transfronterizo de Ciudades Amuralladas, 2013), 204 ss.

22. Ramón Calvet nació en Tarragona en 1765 y actuó en las islas Baleares a finales del siglo xvıII en diseño de fortificaciones para Palma. Participó activamente en la guerra de la Independencia siendo ponderada su acción en la batalla de Medina del Carpio en I809, año en que se lo nominó como conde de Montenegro. En I828 todavía actuaba como director subinspector de ingenieros.

23. Mateo Hernández Vega, Ciudad Rodrigo. La catedral y la ciudad (Salamanca: Imprenta Comercial Salmantina, 1935), 353-355. 
españoles y portugueses en estas actuaciones entre I8Io y I8I4. ${ }^{24}$ En efecto, la documentación cartográfica recoge los proyectos de los baluartes exteriores y la dirección de trabajos del ingeniero Ramón Calvet con soluciones un tanto anacrónicas para etapas ya superadas de la fortificación abaluartada tradicional. En I8I8 estaba allí el ingeniero Antonio Bandarán, quien realizó un plano de la ciudad. ${ }^{25}$ Hacia I823 existe también un proyecto del ingeniero Carlos Montenegro y en ninguna cartografía figura De la Vega y Pérez, aunque no se descarta que haya formado parte del grupo que inicialmente trabajó en los cinco reductos exteriores o haya participado de la defensa de Ciudad Rodrigo. A mediados del siglo xIx dichos reductos exteriores ya estaban en ruinas.

En el plano teórico cabe señalar que la confluencia entre la arquitectura académica y la ingeniería militar, en este momento histórico de carácter bélico, hizo posible superar el rechazo frontal que los arquitectos de San Fernando tuvieron respecto a los diseńos realizados por ingenieros militares, a quienes no consideraban habilitados para ejercer la arquitectura civil.

Posteriormente De la Vega y Pérez habría de trabajar en la región de Salamanca donde podemos situarlo en I8Is con un informe sobre el estado del Colegio Mayor Arzobispo Fonseca dirigido a Manuel Rubín de Celis, penitenciario de la Iglesia de Salamanca. Se trataba de un reconocimiento y una tasación global para transformar el Hospital Militar que se había formado en el Colegio con la finalidad de restituirle su uso educativo con 24 colegiales y aposentos para el rector. ${ }^{26}$ Aparentemente las obras no las realizaría nuestro arquitecto. Un colega, el fraile capuchino Joaquín del Niño Jesús, que manifestaba haberse graduado en la Real Academia de San Fernando y también ser maestro mayor de las fortificaciones, analizó el estado de los edificios dos meses después, detallando sólo la existencia de goteras y seguramente por ello ofrecería realizar la tarea a un precio sensiblemente menor. ${ }^{27}$

Parecería de esta manera perfilarse que la actuación de De la Vega y Pérez se mantuvo dentro del campo de la arquitectura civil más allá de las nominaciones que eventualmente las autoridades locales le adjudicaran. Como no he

24. Cobos y Campos, Almeida-Ciudad Rodrigo, 215 ss. Planos en las páginas 4I7, 438 y 459. 25. Servicio Histórico Militar, Catálogo General de la Cartoteca, vol. I (Madrid, I98I), 87, núm. 3.I74.

26. Manuel Sendín Calabuig, El Colegio Mayor del Arzobispo Fonseca en Salamanca (Universidad de Salamanca, I977), doc. XLIV, I de abril de I8I5, 315.

27. Sendín Calabuig, El Colegio Mayor, doc. XLV, 28 de junio de I8I5, 316. 
DOI: http://dx.doi.org/10.22201/iie.18703062e.2015.107.2556

152

RAMÓN GUTIÉRREZ

encontrado otros registros sobre sus actuaciones me es difícil valorar una trayectoria que vaya más allá de su primera década profesional.

Si bien esto deja abierta una línea para nuevas investigaciones sobre su posible actuación, es claro que su interés hacia temas de carácter tecnológico y militar estuvo condicionado por el contexto en el que le tocó desarrollar su tarea. De esta forma, la trayectoria del primer arquitecto americano, graduado en la Real Academia de San Fernando en tiempos en que se cerraba el dominio español sobre buena parte de América, deja planteados interrogantes sobre una actuación que no está del todo registrada en la fragmentariamente estudiada arquitectura española del siglo XIX. \& 

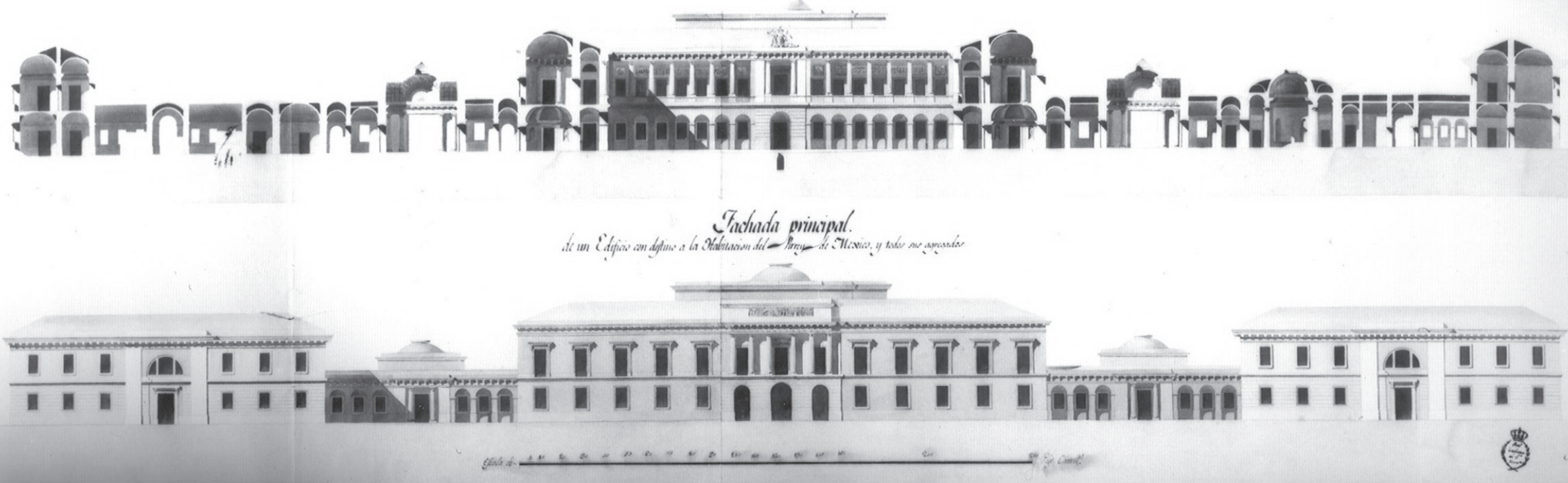

I. Fachada principal y corte A-B del Palacio Virreinal de la Nueva España. Archivo de la Real Academia de Bellas Artes de San Fernando, Madrid. 


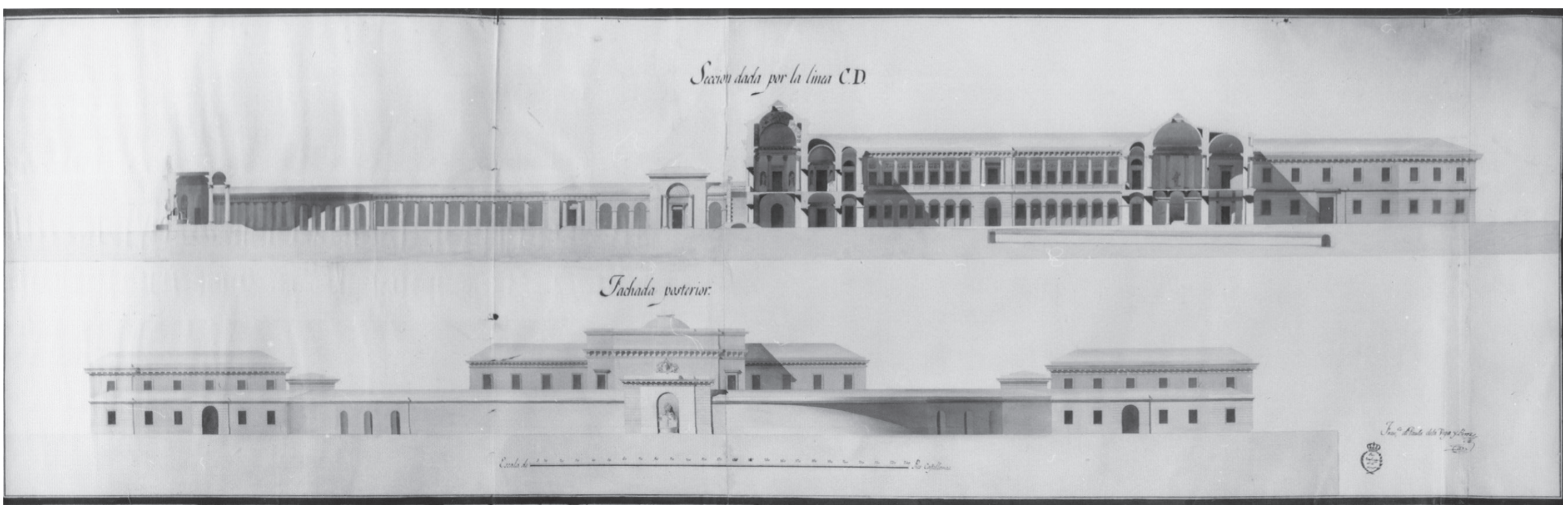

2. Fachada posterior y corte C-D del palacio virreinal de la Nueva Espańa. Archivo de la Real Academia de Bellas Artes de San Fernando, Madrid. 


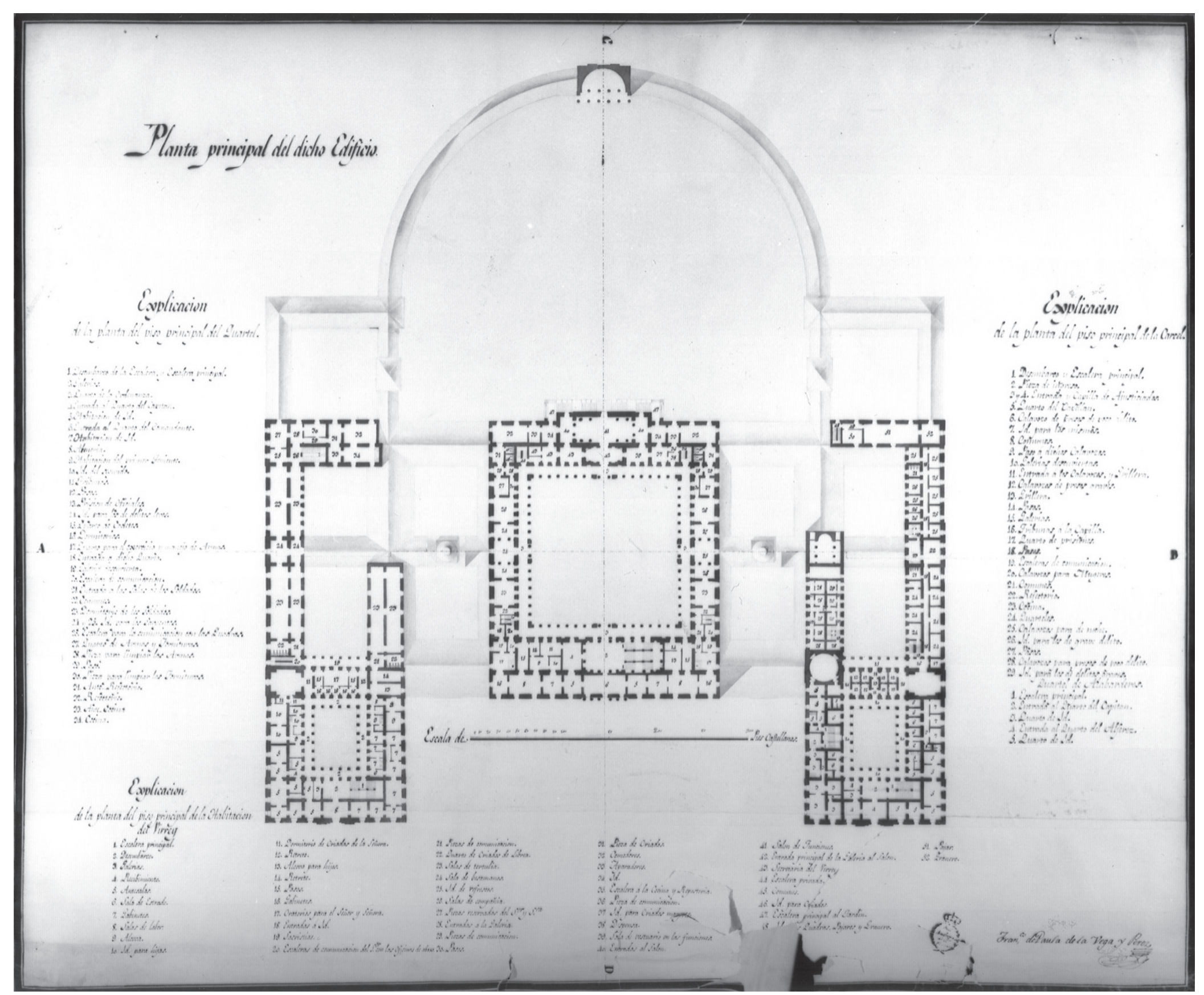

3. Planta principal del Palacio Virreinal de la Nueva España. Archivo de la Real Academia de Bellas Artes de San Fernando, Madrid. 


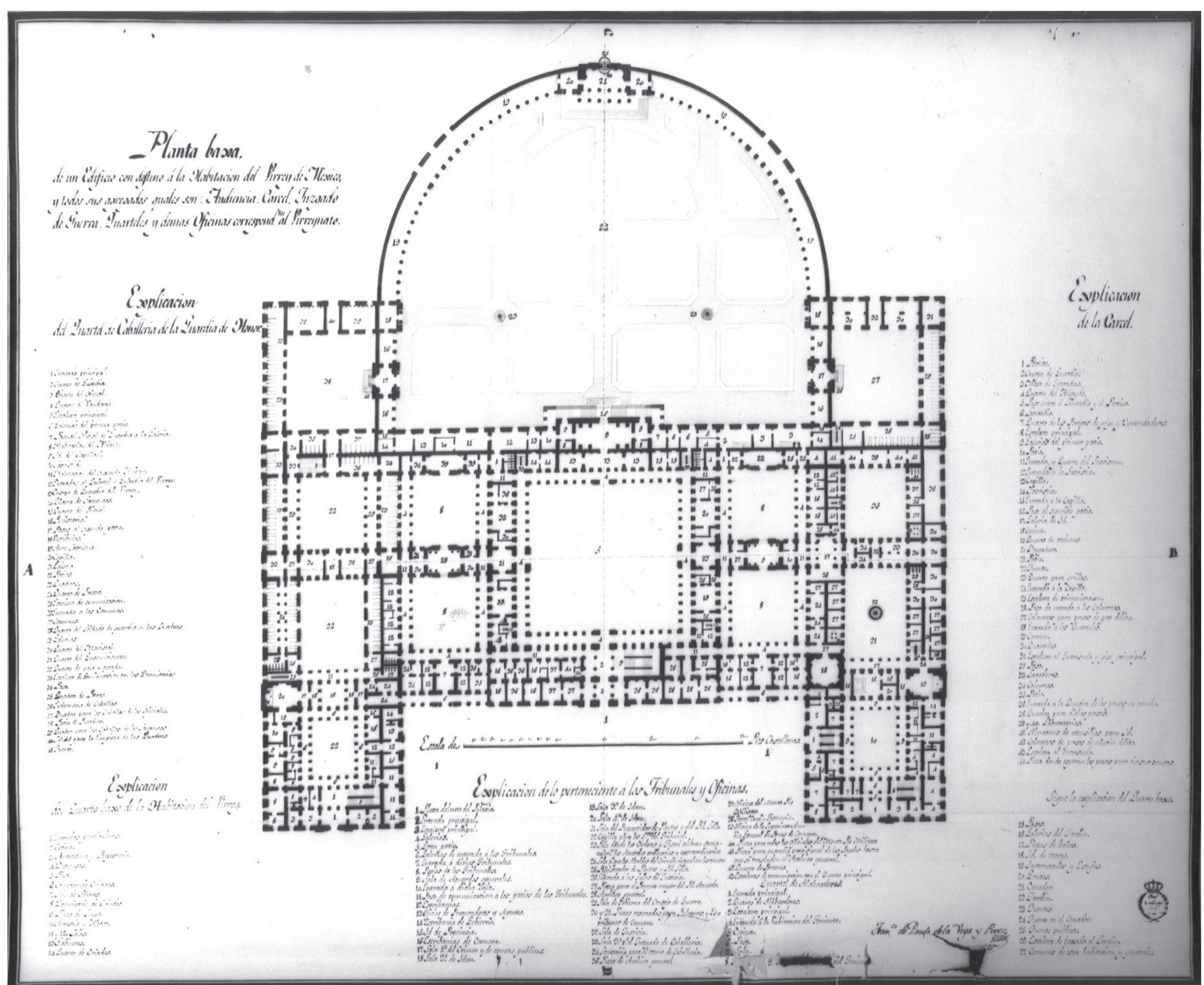

4. Planta baja del Palacio Virreinal de la Nueva Espańa. Archivo de la Real Academia de Bellas Artes de San Fernando, Madrid. 